\title{
Ventilatory sensitivity to mild asphyxia: prone versus supine sleep position
}

\author{
B C Galland, D P G Bolton, B J Taylor, R M Sayers, S M Williams
}

\begin{abstract}
Aims-To compare the effects of prone and supine sleep position on the main physiological responses to mild asphyxia: increase in ventilation and arousal.

Methods-Ventilatory and arousal responses to mild asphyxia (hypercapnial hypoxia) were measured in 53 healthy infants at newborn and 3 months of age, during quiet sleep (QS) and active sleep (AS), and in supine and prone sleep positions. The asphyxial test mimicked face down rebreathing by slowly altering the inspired air: $\mathrm{CO}_{2}$, maximum $5 \%$ and $\mathrm{O}_{2}$, minimum $13.5 \%$. The change in ventilation with inspired $\mathrm{CO}_{2}$ was measured over 5-6 minutes of the test. The slope of a linear curve fit relating inspired $\mathrm{CO}_{2}$ to the logarithm of ventilation was taken as a quantitative measure of ventilatory asphyxial sensitivity (VAS). Sleep state and arousal were determined by behavioural criteria.

Results-At 3 months of age, prone positioning in AS lowered VAS ( 0.184 prone $v$ 0.269 supine, $p=0.050)$. At newborn age, sleep position had no effect on VAS. Infants aged $\mathbf{3}$ months were twice as likely to arouse to the test than newborns $(p=0.013)$. Placing infants prone as opposed to supine increased the chances of arousal 1.57 -fold $(p=0.035)$.

Conclusion-Our findings show 3 month old babies sleeping prone compared to supine have poorer ventilatory responses to mild asphyxia, particularly in AS, but the increased prevalence of arousal is a protective factor.

(Arch Dis Child 2000;83:423-428)
\end{abstract}

Keywords: asphyxia; prone position; supine position; sudden infant death syndrome

Prone sleeping has proved to be the main modifiable risk factor for sudden infant death syndrome. ${ }^{1-3}$ Several mechanisms have been proposed to explain the association. One of these is that infants may suffocate when breathing face down into soft bedding as a result of rebreathing their own expired gas and thus become exposed to the combined asphyxial stimulus of hypoxia and hypercapnia. ${ }^{45}$ The prone sleep position as compared to supine enhances sleep and is associated with fewer arousals from both spontaneous and external stimuli. ${ }^{67}$ The effect of sleep position on physiological responses to respiratory stimuli such as rebreathing is unknown.
Prone positioning in healthy preterm and full term infants makes spontaneous breathing easier. Beyond the neonatal period this mechanical advantage is not apparent for the healthy infant and adverse effects of prone sleeping on ventilation and oxygenation have been reported. ${ }^{89}$ The effect of sleep position on ventilatory responses to respiratory stimuli has been documented only in healthy preterm infants, in whom responses to $\mathrm{CO}_{2}$ were enhanced prone compared to supine. ${ }^{10}$ As far as we are aware, sleep position effects on the ventilatory responses to respiratory stimuli of infants at full term or beyond has never been studied.

The purpose of the present study was to compare ventilatory and arousal responses to mild asphyxia in infants sleeping prone and supine and to document the changes with sleep state and age. Our method used a hood to deliver gases slowly so that the build up of $\mathrm{CO}_{2}$ and depletion of $\mathrm{O}_{2}$ was similar to that which an infant would inspire during sleep face down on soft bedding (maximum $5 \% \mathrm{CO}_{2}$; minimum $13.5 \% \mathrm{O}_{2}$ over 5-6 minutes). Gas concentrations and delivery rates were designed to mimic the time course of rebreathing as shown using a mechanical model. ${ }^{5}$ These compare well with those measured directly from a baby breathing face down into soft bedding $(6.4 \%$ over 5.5 minutes). ${ }^{11}$

\section{Methods}

\section{STUDY GROUP}

A total of 53 babies (30 girls, 23 boys) were recruited for the study. Of these, $42(80 \%)$ were studied at newborn age (15-28 days) and again at approximately 3 months of age (77-99 days). A further seven were studied at the newborn age only and four at the 3 month age only. Mean weight at newborn age was 3919 g (range 3040 to $4880 \mathrm{~g}$ ) and at 3 months, 5715 $\mathrm{g}$ (range 4670 to $7180 \mathrm{~g}$ ). All babies were born at Queen Mary Maternity Unit, Dunedin Hospital. Recruitment was by personal contact to mothers whose medical records fitted within our inclusion and exclusion criteria. Exclusion criteria were: living outside the Dunedin area, postnatal illness, major congenital abnormality, or illness at the time of study. Informed written consent was obtained from the parent(s) of all infants. Mothers of all infants were nonsmokers and the majority of babies were breast fed at both study ages. One infant routinely slept prone whereas the others slept on their side or back. Each newborn study was completed in one day, whereas the majority of 3 month studies were completed over two days (at least five days apart). The study was 
approved by the Ethics Committee Otago, Southern Regional Health Authority, Dunedin, New Zealand.

STUDY PROTOCOL

Infants were studied during a morning or afternoon sleep in a quiet research nursery located within Dunedin Public Hospital. The infants were set up for recordings and then fed and positioned on a firm mattress. The first sleep position was determined randomly (not necessarily the preferred position) as either prone or supine and the same baby was then studied later in the opposite sleep position.

Once the infant was asleep, a perspex head box (suitable size for each age) was positioned over the head. Air first flowed through the head box from a Douglas bag at a rate of $6 \mathrm{l} / \mathrm{min}$ (newborn) or $91 / \mathrm{min}$ (3 month) for one minute and then the flow was switched over to the test mix bag containing $5.5 \% \mathrm{CO}_{2}$ and $13 \% \mathrm{O}_{2}$ in $\mathrm{N}_{2}$ which mixed with the contents of the head box to progressively alter the inspired gas mixture as shown in fig 1 . The test mix was delivered for 5-6 minutes maximum or terminated earlier if the infant woke before this. The maximum inspired $\mathrm{CO}_{2}$ and minimum inspired $\mathrm{O}_{2}$ reached were approximately $5 \%$ and $13.5 \%$ respectively. The gas sample probe was suspended within the head box and repositioned with change in sleep position so that it was always $4 \mathrm{~cm}$ directly above the level of the nostril. If possible tests were performed twice in each sleep state and sleep position. If sleep state changed during a test, the test was abandoned. No more than three tests were performed over one hour; 10 minutes was the minimum time between tests. The head positioning was checked so as to avoid spontaneous rebreathing; the majority of infants slept naturally with their face to the side but a few of the 3 month olds who wanted to sleep with their face into the mattress were positioned with their face to the side.
RECORDINGS

The respiratory pattern was measured by inductive plethysmography (Respitrace model 150; Respitrace Co., New York, USA), a technique proposed by Konno and Mead, ${ }^{12}$ which considers that the respiratory system moves with two degrees of freedom of motion; the sum of the displacement detected by bands placed around the ribcage and abdomen equals tidal volume measured at the mouth. In studies of infants and children, there is good correlation between Respitrace sum and tidal volume so long as the studies are short term and in the controlled laboratory setting. ${ }^{10} 1314$

Calibration of the Respitrace is position dependent, ${ }^{15}$ and as we were carrying out our ventilatory tests in two opposing sleep positions, only changes in uncalibrated tidal volume (voltage) and respiratory rate (breaths/ min) from baseline were measured. The sum of the two signals analogous to the cross sectional area of the ribcage and abdomen were weighted routinely with the ratio 10:8. This is not a critical figure if the two compartments are in phase with each other. ${ }^{16}$ If, however, there was some "paradoxical movement", when for part or all of the respiratory cycle the compartments were in opposite phase, this was no longer true, and tidal volumes could not be estimated with confidence. To avoid subjective decisions we compared computed sums of the individual signals, using several weightings, with the standard sum signal. If there were significant differences in the resultant estimates of tidal volume changes then the data were discarded as unreliable.

Heart rate and arterial oxygen saturation $\left(\mathrm{SaO}_{2}\right)$ were measured from the pulse oximeter (Nellcor N-200, Nellcor Hayward, California, USA) with averaging time set to three seconds. The percentage of inspired $\mathrm{O}_{2}$ and $\mathrm{CO}_{2}$ was measured from a Datex gas analyser (Normocorp 200-oxy $\mathrm{CO}_{2}-\mathrm{O}_{2}$, Datex Instumentarium Corp., Helsinki, Finland). The signals from the pulse oximeter, Respitrace, and Datex were

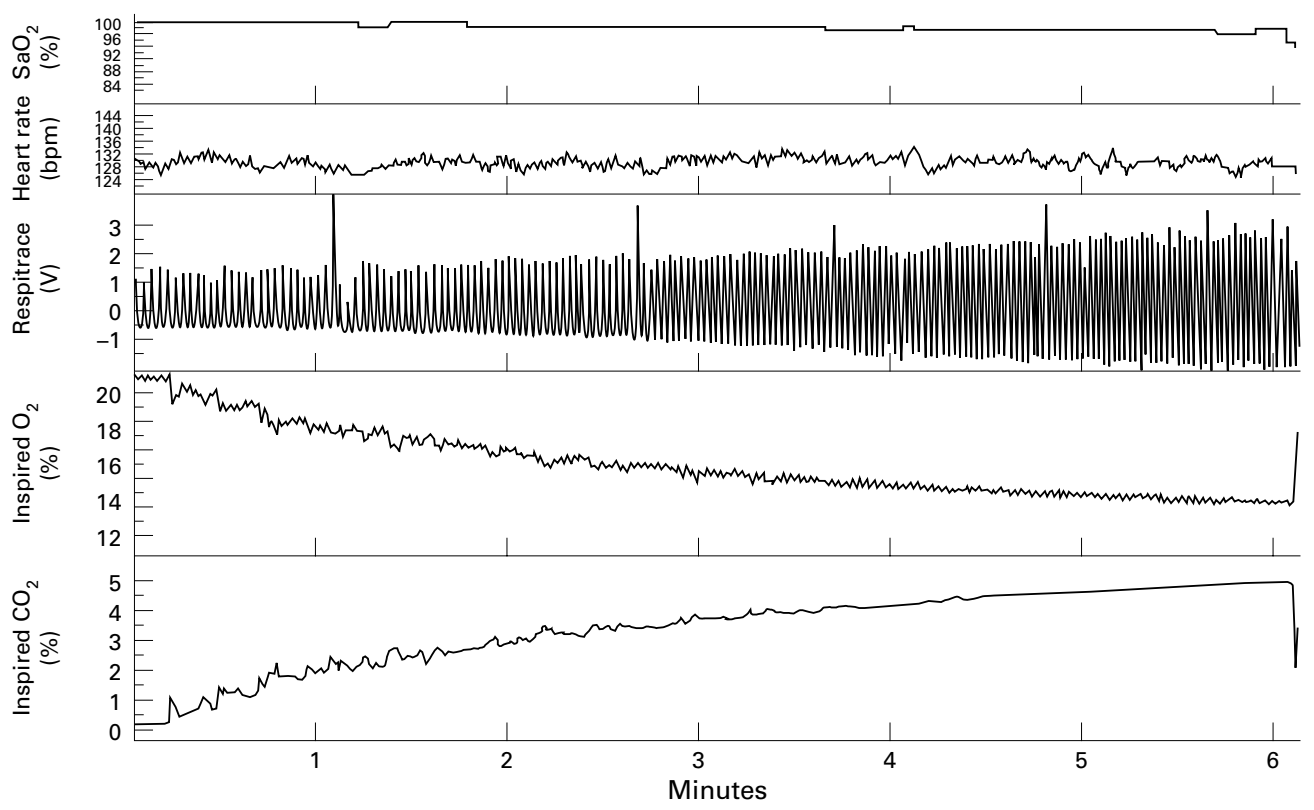

Figure 1 Typical waveforms from an asphyxial test. The subject was a 3 month old infant in quiet sleep. 
Table 1 Baseline values: the effects of age, sleep position, and sleep state on $\mathrm{SaO}_{2}$, heart rate, and respiratory rate

\begin{tabular}{|c|c|c|c|c|c|}
\hline & Constant $^{*}$ & Factor ${ }^{\star}$ & $\Delta t$ & $(95 \% C I)$ & $p$ value \\
\hline \multirow[t]{5}{*}{$\mathrm{SaO}_{2}(\%)$} & \multirow[t]{5}{*}{98.0} & & & $(97.5,98.4)$ & \\
\hline & & Age & 0.7 & $(0.3,1.2)$ & $<0.0001$ \\
\hline & & Sleep state & -0.3 & $(-0.4,-0.06)$ & 0.017 \\
\hline & & Position at newborn & -0.8 & $(-1.2,-0.3)$ & 0.001 \\
\hline & & Position at $3 \mathrm{mth}$ & -0.05 & $(-0.4,0.3)$ & NS \\
\hline \multirow[t]{5}{*}{ Heart rate $(\mathrm{bpm})$} & \multirow[t]{5}{*}{132.7} & & & $(130.2,135.1)$ & \\
\hline & & Age & -10.3 & $(-13.3,-7.4)$ & $<0.0001$ \\
\hline & & Sleep state & 1.5 & $(0.2,2.8)$ & 0.029 \\
\hline & & Position at newborn & 2.2 & $(0.1,4.2)$ & 0.037 \\
\hline & & Position at $3 \mathrm{mth}$ & 6.7 & $(4.6,8.8)$ & 0.001 \\
\hline \multirow[t]{5}{*}{ Respiratory rate (breaths/min) } & \multirow[t]{5}{*}{48.8} & & & $(46.0,51.5)$ & \\
\hline & & Age & -14.5 & $(-17.3,-11.7)$ & $<0.0001$ \\
\hline & & Sleep state & 7.1 & $(5.5,8.7)$ & $<0.0001$ \\
\hline & & Position at newborn & -5.4 & $(-7.9,-3.0)$ & 0.006 \\
\hline & & Position at $3 \mathrm{mth}$ & -0.8 & $(-2.4,0.7)$ & NS \\
\hline
\end{tabular}

^Each factor has a nominated default value; for age this is newborn, for sleep state, QS, and for sleep position, supine. The value for each variable when all the default factors operate is the "constant" and the switching of each factor alters the nominated variable by the difference $(\Delta)$ indicated. For example, the constant for respiratory rate is 48.8 breaths $/ \mathrm{min}$ and there is a fall of $14.5 \mathrm{breaths} / \mathrm{min}$ attributable to taking 3 month data rather than newborn. It does not necessarily follow that the mean respiratory rate was 34.3 breaths/min (48.8-14.5), as other factors may be different in the two age groups, for example, more data obtained in QS. In one case the change associated with altering sleep position is different in the two age groups so these are presented separately.

$\dagger \Delta$ values represent the differences in the direction indicated for:

Age; newborn $\rightarrow 3$ months

Sleep state; QS $\rightarrow$ AS

Position; supine $\rightarrow$ prone.

relayed through the integrated hardware/ software system of the MacLab (ADInstruments Pty Ltd, Australia). Sleep state was determined by watching eye, mouth, hand, and respiratory trace movements based on those described for the two age groups by Guilleminault and Souquet. ${ }^{17}$ Generally quiet sleep (QS) contained regular breathing with no rapid eye movements or facial movements. Active sleep (AS) contained some rapid eye movements, irregular breathing, and sometimes hand or mouth movements. Arousal was evident when the infant's eyes were open with vigorous movement and/or crying.

MEASUREMENT OF THE VENTILATORY ASPHYXIAL SENSITIVITY (VAS)

The change in ventilation (product of respiratory rate and tidal volume) associated with the percentage of inspired $\mathrm{CO}_{2}$ was measured every minute over the 5-6 minutes of the asphyxial test. A linear curve fit relating inspired $\mathrm{CO}_{2}$ to the natural logarithm of ventilation as described by Campbell and colleagues ${ }^{18}$ was then used to determine the ventilatory asphyxial sensitivity (VAS). The value of VAS was the slope of that line and was a meas-

Table 2 Final values: data comparing the effects of age, sleep position, and sleep state on $\mathrm{SaO}_{2}$, heart rate, and respiratory rate

\begin{tabular}{|c|c|c|c|c|c|}
\hline & Constant* & Factor & $\Delta t$ & $(95 \% C I)$ & $p$ value \\
\hline $\mathrm{SaO}_{2}(\%)$ & 97.3 & $\begin{array}{l}\text { Age } \\
\text { Sleep state } \\
\text { Position }\end{array}$ & $\begin{array}{r}0.2 \\
-0.2 \\
-0.3\end{array}$ & $\begin{array}{l}(97.0,97.5) \\
(-0.03,0.4) \\
(-0.4,-0.04) \\
(-0.5,-0.1)\end{array}$ & $\begin{array}{l}\text { NS } \\
0.019 \\
0.005\end{array}$ \\
\hline Heart rate (bpm) & 137.9 & $\begin{array}{l}\text { Age } \\
\text { Sleep state } \\
\text { Position }\end{array}$ & $\begin{array}{r}-4.0 \\
2.5 \\
-0.2\end{array}$ & $\begin{array}{l}(136.8,139.1) \\
(-5.4,-2.7) \\
(1.3,3.7) \\
(-1.4,1.1)\end{array}$ & $\begin{array}{l}<0.0001 \\
<0.0001 \\
\text { NS }\end{array}$ \\
\hline Respiratory rate (breaths/min) & 49.2 & $\begin{array}{l}\text { Age } \\
\text { Sleep state } \\
\text { Position }\end{array}$ & $\begin{array}{r}-4.0 \\
3.3 \\
-0.4\end{array}$ & $\begin{array}{l}(47.5,50.9) \\
(-6.2,-1.8) \\
(1.6,4.9) \\
(-1.6,0.7)\end{array}$ & $\begin{array}{l}0.001 \\
<0.0001 \\
\text { NS }\end{array}$ \\
\hline
\end{tabular}

${ }^{\star}$ Constant is the mean estimate at newborn age, QS state, and supine sleep position. The differences $(\Delta)$ were adjusted for other factors in the model and the baseline value centred at the mean. $\dagger \Delta$ values represent the differences in the direction indicated for:

Age; newborn $\rightarrow 3$ months

Sleep state; QS $\rightarrow$ AS

Position; supine $\rightarrow$ prone. ure of the sensitivity of the ventilatory system to the asphyxial test.

\section{STATISTICAL ANALYSES}

For every infant a mean baseline value for each asphyxial test was obtained for $\mathrm{SaO}_{2}$, respiratory frequency, tidal volume, and heart rate over a period of 10 breaths immediately before delivery of the test gas. Mean values for the same variables were then taken over the 10 breaths immediately before the test was stopped (final values). A single value for VAS was obtained for each test. As the data from these babies involves analysis of many interacting factors, a multivariate analysis isolating the effect of each factor in turn was adopted. This procedure is described in the manual for the statistical package used (STATA, Stata Statistical Software: Release 6.0, Stata Corporation, College Station, Texas, USA). ${ }^{19}$ All the observations and interactions were considered for inclusion in the model for regression analysis. This means that the standard errors and the significance of the statistical tests were based on the number of babies rather than the number of observations in the study. Main effects were analysed for age, sleep state, and sleep position and because the interaction effect between these factors was statistically significant for position, its effect was estimated within each age level and sleep state. Logistic regression was used to compare arousal data for the three variables. Differences were considered statistically significant at $\mathrm{p} \leqslant 0.05$.

\section{Results}

Figure 1 shows a typical example of an asphyxial test and recorded variables. Table 1 presents data for baseline $\mathrm{SaO}_{2}$, heart rate, and respiratory rate. The data are presented as the changes in stated variables with change of individual "factors", age, sleep state, or position. Baseline $\mathrm{SaO}_{2}$ increased significantly with age, was lower in AS compared to QS, and lower prone compared to supine $(\mathrm{p}=0.007)$; significant at newborn age only. Heart rate decreased 
Table 3 VAS: mean (SEM) values presented by age, sleep state, and sleep position and statistical summary

\begin{tabular}{|c|c|c|c|c|c|}
\hline & & \multicolumn{2}{|l|}{ Newborn } & \multicolumn{2}{|l|}{3 months } \\
\hline & & Supine & Prone & Supine & Prone \\
\hline \multirow[t]{6}{*}{ VAS } & QS & $0.250(0.013)$ & $0.252(0.015)$ & $0.282(0.011)$ & $0.268(0.011)$ \\
\hline & AS & $0.207(0.018)$ & $0.205(0.019)$ & $0.269(0.019)$ & $0.183(0.017)$ \\
\hline & & \multicolumn{4}{|l|}{ Statistical summary } \\
\hline & & tム Position at newborn & $p$ value & t\ Position at 3 months & pvalue \\
\hline & QS & $-0.002(-0.37,0.032)$ & NS & $0.014(-0.019,0.046)$ & NS \\
\hline & AS & $0.001(-0.042,0.045)$ & NS & $0.085(0.031,0.029)$ & 0.050 \\
\hline
\end{tabular}

Values in brackets represent $95 \%$ CI.

$\dagger \Delta$ values represent the differences in the direction indicated for position from supine to prone.

with age, was higher prone, and higher in AS. There was a significant interaction effect of sleep position with age $(\mathrm{p}=0.004)$; the higher heart rate prone was significantly greater at 3 months of age. Overall baseline respiratory rate decreased significantly with age, was higher in AS than QS, but was less prone compared to supine. There was a significant interaction effect of sleep position with age; the lower respiratory rate prone compared to supine at 1 month ( -5.4 breaths $/ \mathrm{min})$ was not significant by 3 months of age ( -0.8 breaths $/ \mathrm{min})$.

At the end of the asphyxial test, all final values were significantly different from baseline $(\mathrm{p}<0.0001)$. Mean estimates for the changes were as follows: $\mathrm{SaO}_{2},-0.9 \%(\mathrm{CI}-1.1,-0.7)$; heart rate, +6.7 beats/min (CI 5.8, 7.5); respiratory rate, +5.7 breaths $/ \mathrm{min}$ (CI 3.6, 6.4). Tests that terminated in arousal showed no difference in these variables compared with nonarousal tests. By the end of the test, final $\mathrm{SaO}_{2}$ values were similar for age but still significantly lower in AS and in the prone position (table 2). Heart rate and respiratory rate were now unaffected by sleep position. Mean final values of inspired $\mathrm{CO}_{2}$ and $\mathrm{O}_{2}$ were $4.84 \%$ (CI 4.82, 4.86 ) and $13.99 \%$ (CI 13.95, 14.03) respectively when tests resulted in no arousal. When arousal occurred, the test was terminated early and the inspired gas levels were therefore less changed from room air $\left(0.60 \%\right.$ less for $\mathrm{CO}_{2}$ and $1.0 \%$ more for $\left.\mathrm{O}_{2} ; \mathrm{p}<0.0001\right)$. Arousals were more common in older babies and in AS sleep (see below).

VAS is the slope of inspired $\mathrm{CO}_{2}$ plotted against the natural logarithm of ventilation; the mean correlation coefficients were 0.85 for QS and 0.67 for AS. Table 3 presents mean values of VAS by age, sleep state, and sleep position together with a statistical summary. At newborn age, sleep position had no significant

Table 4 Prevalence of arousal to the asphyxial test

\begin{tabular}{|c|c|c|c|c|c|}
\hline & & \multicolumn{2}{|l|}{ Newborn } & \multicolumn{2}{|l|}{3 month } \\
\hline & & Supine & Prone & Supine & Prone \\
\hline \multirow[t]{7}{*}{ Arousal } & QS & $2 / 65(3.0 \%)$ & $5 / 67(7.5 \%)$ & $2 / 71(2.8 \%)$ & $8 / 68(11.8 \%)$ \\
\hline & Active & $15 / 76(19.7 \%)$ & $10 / 74(13.5 \%)$ & $13 / 55(23.6 \%)$ & $26 / 67(38.8 \%)$ \\
\hline & & \multicolumn{4}{|c|}{ Statistical summary } \\
\hline & Factor & Odds ratio & $C I$ & \multicolumn{2}{|l|}{$p$ value } \\
\hline & Age & 2.03 & $(1.16,3.57)$ & \multicolumn{2}{|l|}{0.013} \\
\hline & Sleep state & 4.90 & $(2.7,8.94)$ & \multicolumn{2}{|l|}{$<0.0001$} \\
\hline & Position & 1.57 & $(1.03,2.39)$ & \multicolumn{2}{|l|}{0.035} \\
\hline
\end{tabular}

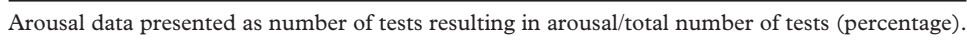

effect on VAS (in either QS or AS). However at 3 months of age VAS was significantly lower when infants were sleeping prone compared to supine, but only in AS.

Table 4 gives the incidence of arousal from the asphyxial test. Age, sleep state, and sleep position all caused significant changes. Infants aged 3 months were twice as likely to arouse to the test than newborn infants. The test given in AS compared to QS increased the chances of arousal fivefold and placing infants prone as opposed to supine increased the chances of arousal 1.57 -fold. There were no interaction effects.

\section{Discussion}

The main finding of this study was that prone positioning of 3 month old infants resulted in a reduction in ventilatory sensitivity to the asphyxial test compared to supine positioning and this effect occurred during active sleep only. The findings add support to the evidence that prone positioning, at the age at which infants are at greatest risk of sudden infant death syndrome (SIDS), can depress or adversely effect normal physiological responses. $^{72021}$ In our study, at newborn age, sleep position had no effect on ventilatory responses.

The asphyxial challenge applied in active sleep, irrespective of position and age, always resulted in a decreased ventilatory response compared with quiet sleep, supporting the findings of others. ${ }^{1822} 23$ This decreased response is thought to occur because of the loss of intercostal muscle tone resulting in a decrease in the ribcage contribution to ventilation during $\mathrm{CO}_{2}$ testing, ${ }^{22}$ inhibition of abdominal muscle recruitment, ${ }^{23}$ and a decrease in central output to the diaphragm. ${ }^{24}$ In considering why the response should be further attenuated in 3 month old infants sleeping prone compared to supine and not in newborns, we speculate that weight of the heavier 3 month old could be an additional factor imposing a mechanical limitation to effective lung expansion. The greater force required to expand the thoracic cage could explain the attenuated ventilatory response. Although this effect of extra weight would also be a factor in infants sleeping prone in quiet sleep, maintenance of intercostal tone may have ensured effective lung expansion. Our own observations were that the newborn infant tended to sleep prone with knees tucked up, leaving a gap 
between abdomen and mattress, whereas the 3 month old infant tended not to tuck his/her knees up and the much larger abdomen was compressed against the mattress. In the adult, the prone position can alter respiratory mechanics, decreasing compliance as the abdomen is compressed, and restricting chest wall movement. ${ }^{25} 26$

Prone positioning generally improves lung function and respiratory drive in preterm and full term newborn infants with or without respiratory illness. ${ }^{27}{ }^{28}$ Beyond the newborn period there is no advantage to ventilation in healthy infants sleeping prone. ${ }^{6}{ }^{29}$ Our data support this in that respiratory rate decreased at newborn age with prone positioning suggesting improved ventilation, but at 3 months of age, changing position made no difference. Martin et $a l$, in a study of healthy preterm infants, found that the ventilatory response to hypercapnia alone in healthy preterm infants was enhanced with prone positioning. ${ }^{10}$ This is opposite to what we found at 3 months of age with hypercapnia/hypoxia. It is difficult to compare the two studies given the disparate ages and differences in methodology; what is consistent is that both studies show an advantage to ventilation in young infants sleeping prone. As the infants get older and reach the age that they are at highest risk of SIDS (3 months), the present study goes on to expose a disadvantage to ventilation with prone sleeping.

Our finding of higher baseline heart rate prone compared to supine has been previously reported in a study in which higher skin temperatures were also measured. ${ }^{30}$ This links with the finding that sleeping prone reduces the exposed surface area available for heat exchange and increases metabolic rate. ${ }^{31}{ }^{32}$ Our reported changes in heart rate, though consistent with this, were minimal.

Arousal, most often associated with lifting and/or turning of the head, is seen as a primary defence against asphyxia-that is, if in a real situation, the baby was breathing face down into soft bedding, lifting and/or turning of the head would allow the baby to breathe fresh air and waking would allow conscious control of a movement and crying if necessary. We acknowledge that the airway protective measure of head lifting or turning alone can occur before full arousal, ${ }^{33}$ but this alone was not an appropriate end point for us. The prone position compared to supine restricted head movement involving lifting, particularly in the younger infants. Therefore the criteria of eyes open and or crying was chosen as the end point for arousal suitable to compare both sleep positions. Even full arousal may not be enough of a defence if the baby was under the covers of the bedclothes or unable to move away from the asphyxiating surface, for example, a hollow in a polystyrene pillow. ${ }^{4}$

The general consensus is that prone positioning enhances sleep, reducing movement ${ }^{30}$ and arousal, either spontaneous ${ }^{630}$ or provoked. ${ }^{20}$ Our previous work supports this consensus in that 3 month old infants sleeping prone compared to supine were less likely to arouse in active sleep to a head up tilt test. ${ }^{7}$ However in the present study we found the opposite effect of sleep position on arousalthat is, at 3 months of age and in active sleep, infants aroused more readily to the asphyxial test in prone sleep compared to supine, probably because of the attenuated ventilatory response allowing more change in blood gases. The prone position in the heavier 3 month old baby with the low intercostal muscle tone of active sleep results in a greater inspiratory effort to achieve normal response from lung mechanoreceptors. This is a recognised cause of dyspnoea ${ }^{34}$ and presumably of arousal. In quiet sleep when ventilatory responses were good, arousal from the asphyxial test was much less common, irrespective of age or sleep position.

The fact that the infants aroused more readily in active sleep is reassuring for the infants studied here who were at very low risk of SIDS. However, babies who have died of SIDS have neuropathological findings suggestive of delayed development in areas of the brainstem responsible for cardiorespiratory control and arousal. ${ }^{35} \mathrm{~A}$ vulnerable infant who at a critical time in development fails to respond and arouse to an exogenous stressor such as those associated with the prone position could go on to die of SIDS as proposed by Filiano and Kinney. ${ }^{36}$

$\mathrm{O}_{2}$ saturation levels never became clinically low nor were there any heart rate changes of clinical significance, emphasising the safety of our protocol and the mild nature of the asphyxial stimulus. The increase in ventilation associated with the hypercapnic stimulus minimised the fall in alveolar oxygen levels, thus preventing any significant fall in oxygen saturation. With the combination of factors resulting in a decreased ventilatory response to the asphyxial test ( 3 month, prone, and in active sleep), $61.2 \%$ of the tests resulted in no arousal. We do not know what would have happened had the test been able to continue beyond the limits of our protocol. If an infant still did not wake, failure to mount an appropriate ventilatory response could have fatal consequences. Chiodini and Thach ${ }^{11}$ have studied infants naturally sleeping face down into soft bedding. One infant reached $85 \%$ saturation in response to accumulation of $6.4 \%$ $\mathrm{CO}_{2}$ with a $\mathrm{PaCO}_{2}$ of $66 \mathrm{~mm} \mathrm{Hg}$, at which time they moved the infant to the face to side position. Other studies testing hypoxia and hypercapnia report infants with poor ventilatory responses ${ }^{16}{ }^{37}$ and/or suppressed arousal. ${ }^{38} 39$

Currently the prone sleep position is without doubt the major risk factor for SIDS. We speculate from our findings that infants sleeping face down who do not mount an appropriate ventilatory response to asphyxia and who do not arouse, may go on to die of SIDS. This would be most likely to occur in infants greater than 1 month of age and occur in active sleep.

This work was supported by a grant from the Health Research Council of New Zealand. We are grateful to the families whose infants were part of this study. 
1 Engelberts AC, de Jonge GA. Choice of sleeping position for infants: possible association with cot death. Arch Dis Child infants: possible

2 Mitchell EA, Taylor BJ, Ford RPK, et al. Four modifiable and other risk factors for cot death: the New Zealand study. 7 Paediatr Child Health 1992;28:S3-8.

3 Ponsonby A, Dwyer T, Kasl SV, Cochrane JA, Newman NM. An assessment of the impact of public health activities to reduce the prevalence of the prone sleeping position during infancy: the Tasmanian cohort study. Prev Med 1994;23:402-8

4 Kemp JS, Thach BT. Sudden death in infants sleeping on polystyrene-filled cushions. N Engl f Med 1991;324:185864.

5 Bolton D, Taylor B, Campbell A, Galland B, Cresswell C. Rebreathing expired gases from bedding: a cause of cot death? Arch Dis Child 1993;69:187-90.

6 Kahn A, Groswasser J, Sottiaux M, Rebuffat E, France P, Dramaix M. Prone or supine body position and sleep charDramaix M. Prone or supine body position and

7 Galland BC, Reeves G, Taylor BJ, Bolton DP. Sleep position, autonomic function, and arousal. Arch Dis Child position, autonomic

8 Poets CF, Rudolph A, Neuber K, Buch U, Von Der Hardt $\mathrm{H}$. Arterial oxygen saturation in infants at risk of sudden death: influence of sleeping position. Acta Paediatr 1995;84:379-82.

9 Uchigasi S, Mukai T, Yamaguchi N, et al. Arterial oxygen saturation monitoring of sleeping infants by pulseoximeter. Fapan f Leg Med 1995;49:87-91.

10 Martin RJ, DiFiore JM, Korenke CB, Randal H, Miller MJ, Brooks LJ. Vulnerability of respiratory control in healthy preterm infants placed supine. F Pediatr 1995;127:609-14.

11 Chiodini BA, Thach BT. Impaired ventilation in infants sleeping facedown: potential significance for sudden infant death syndrome. $\mathcal{F}$ Pediatr 1993;123:686-92.

12 Konno K, Mead J. Measurement of the separate volume changes of rib cage and abdomen during breathing. $\mathcal{F} A p p l$ Physiol 1967;22:407-22.

13 Tabachnik E, Muller N, Toye B, Levison H. Measurement of ventilation in children using the respiratory inductive of ventilation in children using the respirt
plethysmograph. F Pediatr 1981;99:895-9.

14 Dolfin T, Duffty P, Wilkes DL, Bryan MH. Calibration of Dolfin T, Duffty P, Wilkes DL, Bryan $\mathrm{MH}$. Calibration of
respiratory induction plethysmography (Respitrace) in

15 Sackner MA, Watson H, Belsito AS, et al. Calibration of respiratory inductive plethysmograph during natural breathing. F Appl Physiol 1989;66:410-20.

16 Bolton DPG. The prevalence of immature respiratory control in a neonatal population. N Z Med f 1990;103:89-92

17 Guilleminault C, Souquet M. Sleep states and related pathology. In: Korobkin R, Guilleminault C, eds. Advances in perinatal neurology. New York: Spectrum Publications Inc., 1979:225-47.

18 Campbell AJ, Bolton DPG, Taylor BJ, Sayers RM. Responses to an increasing asphyxia in infants: effects of age and sleep state. Respir Physiol 1998;112:51-8.

19 Stata Corp. User's guide. Stata Statistical Software: Release 6.0. College Station, TX: Stata Corporation, 1999:256-60

20 Franco P, Pardou A, Hassid S, Kahn A. Decreased cardiac responses to auditory stimulation during prone sleep. Pediatrics 1996;97:174-8.
21 White M, Beckett M, O'Regan M, Matthews T. Autonomic function and SIDS. Acta Paediatr 1993; (suppl 389):105-6. 22 Honma Y, Wilkes D, Bryan MH, Bryan AC. Rib cage and abdominal contributions to ventilatory response to $\mathrm{CO}_{2}$ in infants. F Appl Physiol 1984;56:1211-16.

23 Praud J-P, Egreteau L, Benlabed M, Curzi-Dascalova L, Nedelcoux H, Gaultier C. Abdominal muscle activity during $\mathrm{CO}_{2}$ rebreathing in sleeping neonates. F Appl Physiol 1991;70:1344-50.

24 Moriette G, Van Reempts P, Moore M, Cates D, Rigatto H. The effect of rebreathing $\mathrm{CO}_{2}$ on ventilation and diaphragmatic electromyography in newborn infants. Respir Physiol 1985;62:387-97.

25 Stone JG, Khambatta HJ. Pulmonary shunts in the prone position. Anaesthesia 1978;33:512-17.

26 Kaneko K, Milic-Emili J, Dolovich MB, Dawson A, Bates DV. Regional distribution of ventilation and perfusion as a function of body position. F Appl Physiol 1966;21:767-77.

27 Adams JA, Zabelta IA, Sackner MA. Comparison of supine and prone noninvasive measures of breathing patterns in fullterm newborns. Pediatr Pulmonol 1994;18:8-12.

28 Wolfson MR, Greenspan JS, Deoras KS, Allen JL, Shaffer TH. Effect of position on the mechanical interaction between the rib cage and abdomen in preterm infants. 7 between the rib cage and ab

29 Orr WC, Stahl ML, Duke J, et al. Effect of sleep state and position on the incidence of obstructive and central apnea in infants. Pediatrics 1985;75:832-5.

30 Skadberg BT, Markestad T. Behaviour and physiological responses during prone and supine sleep in infancy. Arch Dis Child 1997;76:320-4.

31 Nelson EAS, Taylor BJ, Weatherall IL. Sleeping position and infant bedding may predispose to hyperthermia and
sudden infant death syndrome. Lancet $1989 ; \mathbf{i}: 199-201$.

32 Bolton DPG, Nelson EAS, Taylor BJ, Weatherall IL. Thermal balance in infants. $\mathcal{F}$ Appl Physiol 1996;80:2234-42.

33 Lijowska AS, Reed NW, Chiodini BA, Thach BT. Sequential arousal and airway-defensive behavior of infants in asphyxial sleep environments. F Appl Physiol 1997;83: 219-28

34 Killian KJ, Gandevia SC, Summers E, Campbell EJM. Effect of increased lung volume on perception of breathlessness, effort, and tension. F Appl Physiol 1984;57: 686-91.

35 Kinney HC, Filiano JJ, Sleeper LA, Mandell F, ValdesDapena $M$, White WF. Decreased muscarinic receptor binding in the arcuate nucleus in sudden infant death syndrome. Science 1995;269:1446-50.

36 Filiano JJ, Kinney HC. A perspective on neuropathologic findings in victims of the sudden infant death syndrome. Biol Neonate 1994;65:194-7.

37 Shannon DC, Kelly DH, O'Connell K. Abnormal regulaion of ventilation in infants at risk for sudden-infant-death syndrome. N Engl F Med 1977;297:747-50.

38 Davidson Ward SL, Bautista DB, Keens TG. Hypoxic arousal responses in normal infants. Pediatrics 1992;89: $860-4$.

39 Dunne KP, Fox GPP, O'Regan M, Mathews TG. Arousal responses in babies at risk of sudden infant death syndrome at different postnatal ages. Ir Med f 1992;85:19-22. 